\title{
Arranging a conflict on a dairy farm, a case-report: The veterinarian as a process coach
}

\author{
Noordhuizen $\mathbf{J}^{1 *}$ and Edmondson $\mathrm{P}^{2}$ \\ ${ }^{1}$ Certified EC BHM- and Royal DAVM-Specialist in Cattle Herd Health \& Production Management, VACQA-international consultance, Portugal and France, \\ Parnay, France \\ ${ }^{2}$ Specialist in Cattle Health \& Production (Mastitis), Udder Wise, Shepton Mallet, Somerset, UK
}

\begin{abstract}
There are situations on dairy farms, where social interactions or herd performance are hampered due to a series of circumstantial and personal factors. Examples are disputes between parents and children about management and succession; disagreements between a farm manager and his employees; the existence of totally different perceptions of people working on the farm. These examples are not related to the size of a farm. The position of the veterinarian is a special one, because they have a strategic relationship with most of their clients. Most commonly he (or she) has a strong bond with the clients, not in the least based on good knowledge and skills. He knows the farm and the people working on it. This could facilitate acting as a coach trying to solve certain problems which are not specifically veterinary-technical ones.
\end{abstract}

\section{Introduction}

There are situations on dairy farms, where social interactions or herd performance are hampered due to a series of circumstantial and personal factors. Examples are disputes between parents and children about management and succession; disagreements between a farm manager and his employees; the existence of totally different perceptions of people working on the farm. These examples are not related to the size of a farm. The position of the veterinarian is a special one, because they have a strategic relationship with most of their clients. Most commonly he (or she) has a strong bond with the clients, not in the least based on good knowledge and skills. He knows the farm and the people working on it. This could facilitate acting as a coach trying to solve certain problems which are not specifically veterinary-technical ones.

The current paper is based on a short field case that appeared on the internet and is now adapted to a more general approach. This paper describes a problematic herd performance situation and the way this problem could be solved using a protocol-like approach.

\section{Problem description}

On a dairy farm of 1500 cows, the owner, who is also the manager, was not satisfied with the herd performance. He was convinced that the 23 employees did not do their work properly and were not motivated. There was bullying of employees.

The veterinarian who had been visiting this farm monthly for 8 years for herd health \& productivity management advice had noticed the changes in working atmosphere on the farm.

He asked the manager whether his impressions about the changed working atmosphere were indeed shared by the manager. The manager told the veterinarian about the current problem according to him: milk yield level, health status and reproduction performance could have been much better.
The veterinarian asked whether the manager would be interested in him acting as a moderator-coach trying to improve things; the farmer agreed and his veterinarian told him that the first things he needed to do was to make a list of the manager's complaints and the experiences and perceptions of the employees during two separate meetings during normal working hours on the farm. The manager agreed with this approach.

\section{Actions taken by the vet and reunions}

The veterinarian proposed a calendar-plan of actions ${ }^{1^{*}}$ (see Annex). The first action was to make an inventory of complaints $^{2}$ from the manager, and from the employees. A date, hour and place were set for a weekly meeting that would be at most 2 hours and where refreshments would be provided. Table 1 lists the major issues on both sides.

Note that the veterinarian speaks about "perceptions" in his first draft report. When explaining the inventory findings ${ }^{3}$ (second meeting), he clarifies that perceptions are mixing up: facts, emotions, impressions, opinions, observations. Some of these are partly rational, other partly subjective. When both parties agree with the findings, he tells them that the third step is to discuss all findings with both parties (confrontation step $p^{4}$ ) at the third meeting. Most were surprised at the differences between them.

*the upper score figures refer to the different steps in the coaching process (see also Annex I)

${ }^{\star}$ Correspondence to: Noordhuizen J, Former Diplomate of ECBHM and ECVPM, Certified EC BHM- and Royal DAVM-Specialist in Cattle Herd Health \& Production Management VACQA-international consultance, Portugal and Parnay, France, E-mail: jos.noordhuizen@orange.fr

Received: March 04, 2019; Accepted: March 15, 2019; Published: March 20 2019 
There was common ground that appeared on both sides: better herd performance and this was the point from where to start!

The fourth meeting was with the manager on his own and the vet prepared an organizational outline of the farm structure, with each box representing a specific farm work domain and the number of farm workers assigned to each domain. This was a starting point in structure which could be agreed by all parties.

The manager agreed with the veterinarian that the structure in Figure 1 was correct. He explained that sometimes task adaptations had to be done. The veterinarian explained to the manager that all farm workers together should form a real Team (see Annex 2). This Team comprises several Working Teams.

A Team is a small group of people with complementary skills who are committed to a common goal, to performance targets, to procedures (protocols) to achieve the goals and there they are all mutually accountable (Clutterbuck in [1]).

A Working Team is a small group of interdependent persons who share the same responsibility for given outcomes (e.g. for milkers: a low bulk tank somatic cell count).

In Annex 2 listings are presented of a 'winner,' 'team members', as well as a 'winning team' and its dangers [2].

In the preparatory work for the fourth meeting, the veterinarian told the manager also that, for optimal performance, certain elementary demands should be met (Table 2).

The objective is that the manager should be able to plan timeframes to find the right persons for defined tasks and to assign responsibilities to given Working Teams. One way to do this is to apply knowledge tests and carry out observations regarding hands-on activities such as hoof trimming, colostrum milking \& testing.

A Strengths-and-Weaknesses assessment for each employee would be carried out by the manager. On the basis of the outcomes, employees

Table 1. Overview of major issues forwarded by both parties and as perceived by the vet

\begin{tabular}{|l|l|}
\hline Manager's perceptions & Employees' perceptions \\
\hline They do not want to work properly & $\begin{array}{l}\text { He never listens to remarks about } \\
\text { improvement of herd performance }\end{array}$ \\
\hline They are only interested in their pay & $\begin{array}{l}\text { He acts as a kind of dictator and sets } \\
\text { directives }\end{array}$ \\
\hline They have the wrong attitude \& mentality & He thinks he is never wrong \\
\hline Some appear not to be fit for work & He does not respect our dignity \\
\hline Some do not follow the protocols & He does not trust us \\
\hline They always look miserable & He never has a friendly word to say \\
\hline My goal is better herd performance & We are not understood nor appreciated \\
\hline
\end{tabular}

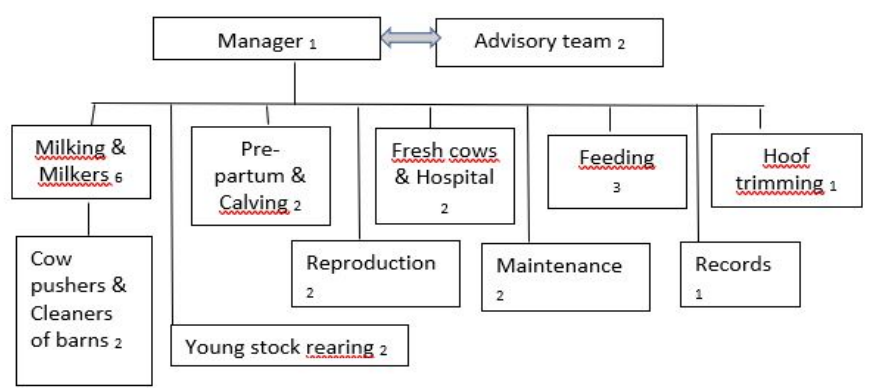

Figure 1. Schematic overview of major farming domains contributing to herd performance. The figures in the boxes refer to the number of people working in that respective domain. The advisory team consists of the veterinarian and the nutritionist. (Source: adapted after [1])
Table 2. The elementary requirements for team building

High level of commitment to clear operational goals set and agreed upon by all Mutual trust between and engagement of manager and employees

Willingness to take risks and share information on a daily basis

Provision of time, money and commitment to employee training when needed

Regular evaluation of Working Team performances

Overall evaluation of the teamwork

would be assigned to specific Working Teams providing the best possible skills to specific work areas.

Note that high performance teams can achieve a return on investment of $\$ 18$ to $\$ 1[3,4]$. [1] presented several features of an effective farm team (Table 3); compare these with the Listings in Annex 2.

Each task must be clearly described. Protocols, also named: Standard Operational Procedures (SOPs), are to be designed in a clear and concise language that employees can understand and comply with. Protocols alone will not do the job; the appropriate attitude and training is a prerequisite for success. Compliance is crucial.

SOPs will lead to a better understanding of exactly what is needed and will lead to better performance. Examples of training includes inserting an oesophageal tube for colostrum feeding; explaining and implementing a protocol for cleaning \& disinfection; body condition scoring, rumen fill scoring; heat detection etc.

The veterinarian discussed these elements with the manager and found out that he would do everything to get herd performance at a higher level and he regained optimism. Together with the veterinarian he developed time planning for the Strengths-and-Weaknesses assessment of employees and set up an inventory list for potential training sessions (e.g. milking hygiene; neonatal calf care; colostrum quality checking and feeding; proper use of drugs, syringes and needles).

The fifth meeting was just with the employees and was an open your eyes step. The veterinarian explained what was needed to improve the working atmosphere and what was to be expected from the manager and the employees.

The veterinarian showed Tables 2 and 3 and explained that a sound "Dairy Team" could be compared to a football team and their coach, the employees being the football players, the farm manager the coach. If one player fails to do what is expected, then the whole team will suffer or, worse, will lose the game [2].

The employees discussed the Tables' contents and asked some clarifying questions and agreed the content. They understood that they had to invest too, and that each employee should undergo a Strengthsand-Weaknesses assessment to find the best role for each individual. They also agreed with the contents of Table 4 on qualities of team members. Most important for them was to be heard, understood and appreciated for work well done and to regain their dignity and to feel being part of the whole enterprise.

Then the next important meeting six gathered the manager and employees for the "solution start step". Immediately the atmosphere was improved, and you could feel that there was positive attitude compared to before.

For this meeting six, rational questions would be asked: (a) what actions are possible? (b) which consequences for each action can be expected? (c) how valuable are these consequences? (d) how is the decision to be made among the alternative actions in terms of value of 
Table 3. Features of an effective farm team

Has clear methods and procedures defined to achieve goals and to focus team efforts

Applies open communication practices

Routinely monitors and discusses personnel performance

Has a skillful manager who facilitate team interactions and assists employees when a problem arises

Has a skillful manager who can execute daily operational work

Provides adequate resources and equipment/facilities to perform defined tasks

Creates a trustful and respectful working environment to allow employees to implement decisions

Table 4. The major qualities of team members on a dairy farm (adapted after Brownstein, 2009, in Scheunemann et al., 2014)

Demonstrates reliability

Communicates constructively

Listens actively to others

Is an active participant

Shares information actively and willingly

Shows commitment to the team

Works as a problem solver

Treats others in a respectful and supportive way

their consequences? [5]. However, it should be clear that these rational issues are impacted by perceptions, opinions and emotions of people involved $[6,7]$.

The manager opened the reunion and said that he was aware of the fact that in the past he had made some errors; but given the fact that he and his employees had the same goal, it was time to let the past behind and "set sails together" for the near future. For that reason, he would like to find the best persons for the different jobs, to arrange for additional training sessions when needed, and to set up communication with all people. He asked whether the employees would like to continue with weekly meetings lasting an hour of which the first 10 minutes would be fully devoted to remarks and questions from the employees. The "yes" answer was unanimous. He also asked the veterinarian to assist at the first three meetings. The manager and the employees thanked the veterinarian for his time, input, engagement and empathy.

Communication is particularly important issue in a working team [8]. It has been stated that communication consists of $15 \%$ words and $85 \%$ of non-verbal expressions. The latter is referred to as "body language". To get a message across, there is a social science-based rule saying that the success of a message is dependent on $5 \%$ knowledge and skills, and $95 \%$ emotions and body language. Body language comprises attitude, volume of language, tone of voice, showing compassion, and implementing the principle of "we" versus "you" or "I". The "we" means that both parties are equally important.

The manager discussed the Strength-and Weakness-Points assessment and listed together with the employees the different dates and times for each of them. On the basis of the Strength-and-Weakness assessment later-on, a few employees changed their roles (two from 'milking' swapped with 'young stock'; one from 'Feeding' changed with one from 'Pre-partum/calving'; one from 'Reproduction' changed with one from 'Fresh cows').

Next, he discussed the Training sessions [9], starting with the new 'Milking' people, one week later. The second training was for the new person at 'Feeding, one week later, followed by the 'Fresh Cow' person, the 'Reproduction' person and the 'Pre-partum' people, etcetera. He installed a white board in each barn, where employees could write down their remarks and observations on cattle, while the manager could write his instructions. Short discussions between manager and employees on the daily work done were scheduled at the end of each day.

\section{Discussion}

In this case study, the process from identifying the problem to starting to solve the problem took 6 weeks (6 meetings, once a week). This was the time needed to bring everyone into alignment and get rid of bad feelings and resentment to make a fresh start.

The manager slowly could see that there was light at the end of the tunnel, while the employees regained their dignity and saw their views and comments were taken into consideration. The manager paid the veterinarian for the time he spent on the process of coaching and understood that the improved herd performance would lead to a payback on this investment. Literature on this issue is rare, but one of the characteristics of Top Dairy Farms is the presence of a true Team on those farms.

The veterinarian worked as a "coach" (see also Annex 2). He could function like one because he knew the farm, the manager and the employees for 8 years. He was spending several hours per month talking and listening to everybody. He was a kind of "natural contactperson" for everyone due to his communication skills. Coaches too can make mistakes, like every other human being, but should not make the same mistake twice; one has to learn from his mistakes. Figure 2 shows the dilemmas of a coach [2].

The veterinarian could assist the manager in preparing practical hands-on trainings focused on individual employees in specific work areas and in the development of Standard Operational Procedures, SOPs. Many practical examples (templates) are provided by [10]. These protocols, once developed, should be explained to staff and training given so that they can be adopted and followed. These will be updated as and when necessary. Compliance to the SOPs is critical for success.

Any veterinarian who would like to start functioning as a coach should undergo training especially on conflict handling. He must understand the "Farmer Profile", his motivations, goals, professional identity issues and opinions [5]. Among these are: his well-being on and off the farm, job satisfaction, discussions with the veterinarian, farm profits, time-allocations to given issues.

On modern dairy farming with entrepreneurial farmers, the veterinarian is regarded as a professional partner and not a fire-brigade service provider for individual cows [11]. He should implement professional communication skills and learn about verbal and nonverbal communication ([8] 'Active listening', [12]).

He will ask open questions (why; who; where; what; which; how) instead of questions which are answered by yes or no. He must really

Figure 2. The dilemmas of a coach.

\begin{tabular}{|l|c|l|}
\hline \multicolumn{3}{|c|}{ The dilemmas of a coach } \\
\hline Focus on performance & versus & Focus on human issues \\
\hline Suppression of emotions & versus & Expression of emotions \\
\hline Keeping distance & versus & Approaching the other \\
\hline Being convinced & versus & Being doubtful \\
\hline Impose discipline & versus & Give liberties \\
\hline Not making mistakes & versus & Taking (some) risks \\
\hline
\end{tabular}

A certain balance between the left and the right sides represents the Coaching Style (adapted after [2]) 
listen to others, summarize what has been said so both sides know that he understands what has been said. Finally, the veterinarian should be aware of the fact that the function as coach requires considerable time input. Several of the forenamed aspects are addressed in detail in Noordhuizen (2012, chapter 'Management').

The management style that is most fruitful for developing a true Team on the farm can be summarized by: The manager who tolerates a wide range of personality styles, who accepts and manages errors, stays calm but firm on decisions, and always rewards/acknowledges success and good work done [1]. With this style, the risk of high personnel turn-over will be much lower because most people, if not all, will experience great job satisfaction. See also the listings in Annex 2 on this subject.

Dairy herds continue to get larger with more employees. It is important that the right management framework is in place. Employees should have a written job description outlining their key duties and how their performance is measured. The farm should have goals such as for fertility performance, calf rearing, production, milk quality etcetera, that are shared with all employees. There should be good and regular communication between management and employees. Simple communication aids can be very effective, like using whiteboards to show how the farm is doing. Team meetings are very useful, e.g. milking team. Training is very important and pays great dividends and stimulates and empowers staff [9]. Any staff issues should be dealt with promptly by management. Annual appraisals of employees can prove highly beneficial. A herd with such an approach to employee management and development is likely to achieve its goals compared to a herd at the start of this case study. Finally, one may consider installing manager-evaluations by employees [13], although this might be seen as a potential threat by managers. It all depends on the prevalence of good relationships on the farm whether this would be a useful exercise once a year.

\section{References}

1. Schuenemann GM, Bas S, Barragan AA, Workman JD (2014) Management and training of dairy personnel with emphasis on teamwork and performance. In: Proceedings of the 50th Florida Dairy Production Conference, Gainesville, FL USA, 21-31.

2. Gerbrands T (2011) Inspiration: coaching and performance. Pharos Publishers, The Netherlands.

3. Rasmussen MD, Frimer ES, Harvath Z, Jensen NE (1990) Comparison of a standardized and variable milking routine. J Dairy Sci 73:3472-3480.

4. Schuenemann, GM, Maquivar MG, Bas S, Workman JD (2013) Effect of milking personnel performance and turnover on milk losses in dairy herds. J Dairy Sci 96: 680.

5. Kristensen E, Jakobsen EB (2011) Challenging the myth of the irrational dairy farmer $N Z$ Vet J 59: 1-7. [Crossref]

6. Valeeva NI, Lam TJGM (2007) Motivation of dairy farmers to improve mastitis management. J Dairy Sci 90: 4466-4477.

7. Haldar L, Fischer L (2008) Giving advice under uncertainty: what you do, what you should do and what others think you do. J Econ Psych 29: 667-683.

8. Kleen JL, Atkinson O, Noordhuizen JPTM (2011) Communication in production anima medicine: a complex interaction with the example of dairy herd health medicine. Ir Vet $J$ 64. [Crossref]

9. Rovai M, Carroll H, Foos R, Erickson T, Garcia A (2016) Dairy Tool Box Talks: a comprehensive worker training in dairy farming. Front Public Health 4: 136. [Crossref]

10. Noordhuizen J (2012) Dairy herd health and Management: a guide for veterinarians and dairy professionals. Context Products Publishers Ltd, Packington, England, UK 472.

11. Noordhuizen JP, van Egmond MJ, Jorritsma R, Hogeveen H, van Werven T, et al. (2008) Veterinary advice for entrepreneurial Dutch dairy farmers: from curative practice to coach-consultant: what needs to be changed? Tijdschr Diergeneeskd 133: 4-8. [Crossref]

12. Edmonson $P$ (2019) Successful communication for farm animal practice - staying ahead in a rapidly changing world. 2019 In: Proceedings of the Dairy Summit 2019, pp 6-12.

13. Durst PT, Moore SJ, Ritter CV, Barkema HW (2018) Evaluation by employees of employer-management on large US dairy farms. J Dairy Sci 101: 7450-7462.

Copyright: (C2019 Noordhuizen J. This is an open-access article distributed under the terms of the Creative Commons Attribution License, which permits unrestricted use, distribution, and reproduction in any medium, provided the original author and source are credited. 